\title{
Abnormal IL-1 Receptor Antagonist Production in Patients with Polymyositis and Dermatomyositis
}

\author{
Kazue Son, Yasuyuki Tomita, Takako Shimizu, Susumu Nishinarita, Shigemasa Sawada and Takashi Horie
}

\begin{abstract}
Objective To examine the relationship between serum levels of interleukin-1 receptor antagonist (IL-1Ra) and its gene expression in peripheral blood mononuclear cells (PBMC) from patients with polymyositis and dermatomyositis (PM/DM).

Methods IL-1Ra levels in sera from patients and supernatants of unstimulated monocyte cultures were measured by enzyme-linked immunosorbent assay. Expression of IL1Ra mRNA was analyzed by Northern blotting, and an 86base pair variable repeat polymorphism in intron 2 of the IL-1Ra gene was determined by polymerase chain reaction.

Results Serum IL-1Ra was significantly elevated in 27 patients with active-stage PM/DM when compared with levels in 16 patients with inactive-stage PM/DM and19 normal controls. Serum concentrations of IL-1Ra were correlated with PM/DM disease activity. IL-1Ra mRNA was detected in freshly isolated PBMC from patients with activestage PM/DM, but not in controls. Moreover, IL-1Ra concentrations were increased significantly in unstimulated monocytes from patients with active-stage PM/DM compared with monocytes from normal controls. However, there were no significant differences in IL-1Ra allele frequencies between patients and normal controls.

Conclusion Elevation of both IL-1Ra mRNA and protein in sera of patients with active-stage PM/DM suggest that higher levels of serum IL-1Ra may reflect increased IL-1Ra production in myositis, and that IL-1Ra may regulate IL-1-mediated muscle fiber damage in PM/DM. (Internal Medicine 39: 128-135, 2000)
\end{abstract}

Key words: IL-1 Ra mRNA, polymorphism

\section{Introduction}

Polymyositis (PM) and dermatomyositis (DM) are inflam- matory muscle diseases that are charcterized clinically by systemic proximal muscle weakness, cutaneous legions (in DM), and systemic manifestations in other organs. Although little is known about the etiologies of these diseases, evidence suggests that both cellular and humoral autoimmune mechanisms are involved in the pathogenesis and progression of PM and DM (PM/DM) (1-3).

Proinflammatory cytokines such as interleukin (IL)-1, tumor necrosis factor (TNF), and IL-6 play roles in the inflammatory processes of many autoimmune diseases. However, the role of these cytokines in PM/DM is poorly understood. Studies of serum cytokines have revealed elevated levels of IL-1 $\alpha$ and soluble IL-2 receptors in patients with active-stage PM/ DM (4). Immunohistochemistry studies of muscle tissue sections have shown IL- $1 \alpha$, IL- $1 \beta$, and transforming growth factor (TGF) $\beta 1-3$ to be expressed in PM/DM patients (5). These findings suggest that IL-1 may be important in the inflammatory process in PM/DM.

A specific inhibitor of IL-1 activities, designated IL-1 receptor antagonist (IL-1Ra), has been identified $(6,7)$. Elevated levels of IL-1Ra in serum/plasma and biological fluids are found in several diseases, and the inhibitory and protective effects of IL-1 Ra against IL-1-mediated diseases have been demonstrated (8-14).

In the present study, we measured IL-1Ra concentrations in sera and in culture supernatants of unstimulated monocytes from patients with the active-stage PM/DM, and analyzed IL-1Ra mRNA expression in freshly isolated peripheral blood mononuclear cells (PBMC) from these patients. The results show that increased serum levels of IL-1Ra are due, at least in part, to increased IL-1Ra production from monocytes in patients with active-stage PM/DM and that IL-1Ra may regulate IL-1-mediated muscle fiber damage in PM/DM.

\section{Patients and Methods}

\section{Patients}

The study group was comprised of 43 patients with PM/ DM (29 women and 14 men; mean age, 49.0 years; range, 15 to 78 years) classified according to the diagnostic criteria of

From the First Department of Internal Medicine, Nihon University School of Medicine, Tokyo

Received for publication June 3, 1999; Accepted for publication September 10, 1999

Reprint requests should be addressed to Dr. Yasuyuki Tomita, the First Department of Internal Medicine, Nihon University School of Medicine, 30-1 Oyaguchikamimachi, Itabashi-ku, Tokyo 173-8610 


\section{IL-1Ra in PM/DM}

the Japanese Ministry of Health and Welfare and 19 normal controls (12 women and 7 men). Disease activity was determined by 1) proximal muscle weakness, 2) elevated serum levels of creatine kinase (CK) and aldolase, 3) myogenic change on electromyogram (EMG), 4) muscle biopsy findings of inflammatory myopathy, and 5) skin lesions such as heliotrope rash or Gottron's sign. Patients who presented with, at least 3 of the 5 features were described as having active disease in this study. Of the 43 patients with PM/DM, 27 (15 PM and 12 DM) were newly diagnosed patients and noted with active stage disease, while 16 had inactive stage disease. All active-stage patients were not receiving prednisolone and inactive-stage patients were receiving $<5 \mathrm{mg}$ of prednisolone at the time of serum sampling. Age, muscle enzyme levels, clinical features, and initial dose of steroid therapy of the active stage PM/DM patients are shown in Table 1.

\section{Serum samples}

Blood obtained by venipuncture was allowed to clot at room temperature for 1 hour. After centrifugation, the serum was stored at $-20^{\circ} \mathrm{C}$ until used. None of the patients had bacterial infections at the time of sampling.

\section{Cell preparation}

PBMC were obtained from heparinized blood from patients with PM/DM and from controls by centrifugation over FicollHypaque (Litton Bionetics, Kensington, MD) for 30 minutes at 1,500 rpm. PBMC were washed three times and resuspended in RPMI 1640 (Irvine, Santa Ana, CA) supplemented with 10\% heat-inactivated fetal bovine serum (Gibco BRL, Gaithersburg, MD). Monocytes were enriched by sequential adherence to plastic as previously described (15). Briefly, PBMC were placed in culture dishes (1007; Falcon, Oxnard, CA) that had been precoated with autologous plasma and incubated at $37^{\circ} \mathrm{C}$ for 2 hours. Non-adherent cells were aspirated and the culture dishes were washed extensively with prewarmed RPMI 1640. After that, adherent cells were collected by scraping with a rubber policeman and washed three times with RPMI 1640. This cell population was designated as the monocyte fraction and had greater than $85 \%$ peroxidase-positive cells.

\section{Measurement of serum IL-1Ra and IL-1 $\beta$ levels}

Serum IL-1Ra and IL-1 $\beta$ levels were measured using commercially available ELISA kits (Amersham International plc, Buckinghamshire, UK). ELISA was performed according to

Table 1. Clinical Features and Muscle Enzyme Levels in 27 Patients with Active PM/DM

\begin{tabular}{|c|c|c|c|c|c|c|c|c|}
\hline PT & Age/Sex & Diagnosis & $\mathrm{CK}^{*}$ & Aldolase & Jo- 1 ※ & $\begin{array}{c}\text { Muscle } \\
\text { weakness }\end{array}$ & $\begin{array}{l}\text { Other clinial } \\
\text { features }^{\S}\end{array}$ & Treatment daily dose ${ }^{\mathbb{t}}$ \\
\hline 1 & $53 / \mathrm{F}$ & PM & 632 & 9.7 & ND & + & AIHA/ITP & PSL45 \\
\hline 2 & $22 / \mathrm{F}$ & PM & 567 & 2.3 & - & + & MCTD & PSL60 \\
\hline 3 & $55 / \mathrm{M}$ & PM & 7,180 & 169.5 & + & + & - & PSL30 \\
\hline 4 & $58 / \mathrm{M}$ & PM & 6,138 & 49.5 & + & + & - & PSL60 \\
\hline 5 & $22 / \mathrm{F}$ & PM & 5,727 & 77.8 & - & - & - & PSL50 \\
\hline 6 & $32 / \mathrm{M}$ & PM & 1,701 & 20.4 & ND & - & - & - \\
\hline 7 & $70 / \mathrm{M}$ & PM & 928 & ND & - & - & - & PSL60 \\
\hline 8 & $15 / \mathrm{F}$ & PM & 223 & 16.2 & - & - & - & PSL40 \\
\hline 9 & $22 / \mathrm{F}$ & PM & 569 & 21.6 & - & + & - & PSL50 \\
\hline 10 & $78 / \mathrm{F}$ & PM & 4,578 & 71.8 & + & + & $\mathrm{PF}$ & PSL50 \\
\hline 11 & $59 / \mathrm{M}$ & PM & 222 & 15.5 & ND & + & $\mathrm{PF}$ & PSL60 \\
\hline 12 & $39 / \mathrm{F}$ & PM & 5,355 & 46.1 & - & + & - & PSL40 \\
\hline 13 & $55 / \mathrm{M}$ & PM & 6,790 & 118.8 & + & + & AIN & PSL60 \\
\hline 14 & $50 / \mathrm{F}$ & PM & 1,754 & 26.6 & - & + & - & PSL60 \\
\hline 15 & $63 / \mathrm{F}$ & PM & 2,239 & 26.4 & - & + & $\mathrm{PF}$ & PSL60 \\
\hline 16 & $16 / \mathrm{M}$ & DM & 7,315 & 51.4 & - & + & - & PSL100 \\
\hline 17 & $53 / \mathrm{M}$ & DM & 5,889 & 66.6 & - & + & - & PSL60 \\
\hline 18 & $31 / \mathrm{F}$ & DM & 4,116 & 55.5 & - & + & - & PSL60 \\
\hline 19 & $78 / \mathrm{F}$ & DM & 2,359 & 6.4 & ND & + & - & PSL50 \\
\hline 20 & $40 / \mathrm{F}$ & DM. & 131 & 7.2 & ND & - & uterine cancer & PSL20 \\
\hline 21 & $40 / \mathrm{M}$ & $\mathrm{DM}$ & 121 & 9.5 & - & + & AIN/RA & mPSL1,000/CY \\
\hline 22 & $47 / F$ & DM & 90 & 10.7 & - & - & $\mathrm{PF}$ & PSL40 \\
\hline 23 & $46 / \mathrm{F}$ & DM & 2,056 & 17.5 & - & + & breast cancer & PSL70 \\
\hline 24 & $48 / \mathrm{F}$ & DM & 4,326 & 21.6 & - & + & - & PSL45 \\
\hline 25 & $67 / \mathrm{F}$ & DM & 2,060 & 22.0 & - & + & - & PSL55 \\
\hline 26 & $73 / \mathrm{M}$ & DM & 4,059 & 125.5 & - & + & - & PSL45 \\
\hline 27 & $76 / \mathrm{M}$ & DM & 632 & 12.0 & - & + & $\mathrm{PF}$ & PSL30 \\
\hline
\end{tabular}

${ }^{*} \mathrm{CK}$ : creatine kinase (IU/l), * ND: not determined, ${ }^{\S} \mathrm{PF}$ : pulmonary fibrosis, AIN: acute interstitial pneumonia, IPSL: prednisolone, mPSL: methylprednisolone, CY: cyclophosphamide. 
the manufacturer's instructions. The sensitivities of the IL-1Ra and IL-1 $\beta$ ELISAs were $22.0 \mathrm{pg} / \mathrm{ml}$ and $2.0 \mathrm{pg} / \mathrm{ml}$, respectively. All samples were assayed in duplicate.

\section{Preparation of $c D N A$ probes}

The 0.56 kilobases $(\mathrm{kb})$ EcoRI-EcoRI fragment of human IL-1Ra cDNA (16) and $0.7 \mathrm{~kb}$ PstI-PvuII fragment of human IL-1 $\beta$ cDNA were kindly provided by Dr. T. Nishida (Otsuka Pharmaceutical Co., Ltd., Tokushima). The 0.77 kb NcoI-TaqI fragment of chicken actin cDNA was purchased from Oncor (Gaithersburg, MD). Purified cDNA (100 ng) was radiolabeled by random primer extension in the presence of ${ }^{32} \mathrm{P}-\mathrm{dCTP}$. The resultant specific activity was approximately $7 \times 10^{8} \mathrm{cpm} / \mathrm{mg}$ which was used at $2 \times 10^{7} \mathrm{cpm}$ per blot.

\section{RNA isolation and Northern blot analysis}

Total cellular RNA was prepared from freshly isolated PBMC using an RNA extraction kit (RNAzol B. TM, Tel-Test, Inc., Friedswoods, TX) and the acid guanidine thiocyanatephenol-chloroform extraction method. Fifteen micrograms of denatured RNA per lane was size-fractionated by electrophoresis on $1 \%$ agarose-formaldehyde gels and then transferred to a nylon membrane (Hybond $\mathrm{N}^{+}$, Amersham, UK) by capillary transfer. The blots were prehybridized for 15 minutes at $65^{\circ} \mathrm{C}$ and then hybridized for 3 hours at $65^{\circ} \mathrm{C}$ in Rapid Hybridization Buffer (Amersham) with ${ }^{32} \mathrm{P}$-labeled cDNA probe. After hybridization, the blots were washed with $0.1 \times \mathrm{SSC} / 0.5 \%$ SDS for 20 minutes at $65^{\circ} \mathrm{C}$ and exposed to Kodak XAR-5 X-ray film (Eastman Kodak Co., Rochester, NY) with an intensifying screen for 16 hours at $-70^{\circ} \mathrm{C}$. For rehybridization, the blots were stripped completely of the IL-1Ra cDNA probe by washing with "stripping buffer" ( $2.5 \mathrm{mM}$ TRIS, $0.1 \mathrm{mM}$ EDTA, $0.025 \%$ sodium pyrophosphate, $0.05 \times$ Denhardt's solution) for 40 minutes at $65^{\circ} \mathrm{C}$ and then rehybridized with the ${ }^{32} \mathrm{P}$-labeled actin cDNA probe for 3 hours at $65^{\circ} \mathrm{C}(17)$.

\section{IL-1Ra gene polymorphism}

Within the second intron of the IL-1Ra gene, the region that contains variable numbers of an identical tandem repeat (VNTR) of 86-base pairs (bp) was amplified by polymerase chain reaction (PCR) (18). The primers flanking this region were: 5' CTCAGCAACACTCCTAT $3^{\prime}$ and $5^{\prime}$ TCC TGGTCTGCAGGTAA 3' (18). Briefly, genomic DNA was extracted from PBMC with a DNA extraction kit (Sepa Gene ${ }^{\mathrm{TM}}$, Sanko Junyaku Co., Japan), that used guanidine thiocyanate digestion, chloroform-sodium acetate extraction, and isopropanol precipitation. The 86-bp tandem repeat polymorphism of the IL-1Ra gene was amplified from genomic DNA in a DNA Thermal Cycler (Perkin Elmer, Norwalk, CT) using the primers described above. DNA was denatured at $96^{\circ} \mathrm{C}$ for 1 minute, and PCR conditions were as follows: 30 cycles at $94^{\circ} \mathrm{C}$ for 1 minute, $60^{\circ} \mathrm{C}$ for 1 minute, and $72^{\circ} \mathrm{C}$ for 2 minutes. The final extension was carried out at $70^{\circ} \mathrm{C}$ for 7 minutes. The amplification products were separated by electrophoresis on $1.7 \%$ agarose gels and stained with ethidium bromide for visualization with UV light. A 100-bp DNA ladder (Gibco BRL, Grand
Island, NY) was used to determine the size of the PCR fragments.

\section{Statistical analysis}

P-values were calculated by Fisher's exact test.

\section{Results}

\section{Serum IL-1Ra and IL-1 $\beta$ levels in PM/DM}

Serum levels of IL-1Ra in the $43 \mathrm{PM} / \mathrm{DM}$ patients and 19 normal controls are shown in Fig. 1; 27 of 43 PM/DM patients had active-stage disease and 16 were in the inactive-stage. Serum IL-1Ra concentrations were significantly higher in the active-stage PM/DM patients (range, 144 to $21,388 \mathrm{pg} / \mathrm{ml}$; mean \pm SE, $4,384 \pm 1,003 \mathrm{pg} / \mathrm{ml}$ ) than in inactive-stage patients (range, 85 to $2,267 \mathrm{pg} / \mathrm{ml}$; mean $\pm \mathrm{SE}, 654 \pm 131 \mathrm{pg} / \mathrm{ml} ; \mathrm{p}<0.01$ ) and in normal controls (range, 11 to $839 \mathrm{pg} / \mathrm{ml}$; mean $\pm \mathrm{SE}$, $354 \pm 54 \mathrm{pg} / \mathrm{ml} ; \mathrm{p}<0.01)$. However, the difference in serum IL1 Ra levels between active-stage DM patients and active-stage PM patients $(4,467 \pm 1,641 \mathrm{pg} / \mathrm{ml}$ for $12 \mathrm{DM}$ vs $4,317 \pm 1,291$ $\mathrm{pg} / \mathrm{ml}$ for $15 \mathrm{PM}$ ) was not significant. Among 27 active-stage PM/DM patients, IL-1Ra levels were higher in patients with severe muscle weakness than in patients with moderate or mild muscle weakness. However, it should be noted that the IL-1Ra levels in active-stage patients were quite variable between patients. The relationship of IL-1Ra to steroid therapy in PM/ DM patients is shown in Fig. 2. Active-stage patients (3 PM and $4 \mathrm{DM}$ patients) received 30 to $100 \mathrm{mg} /$ day of predniso-

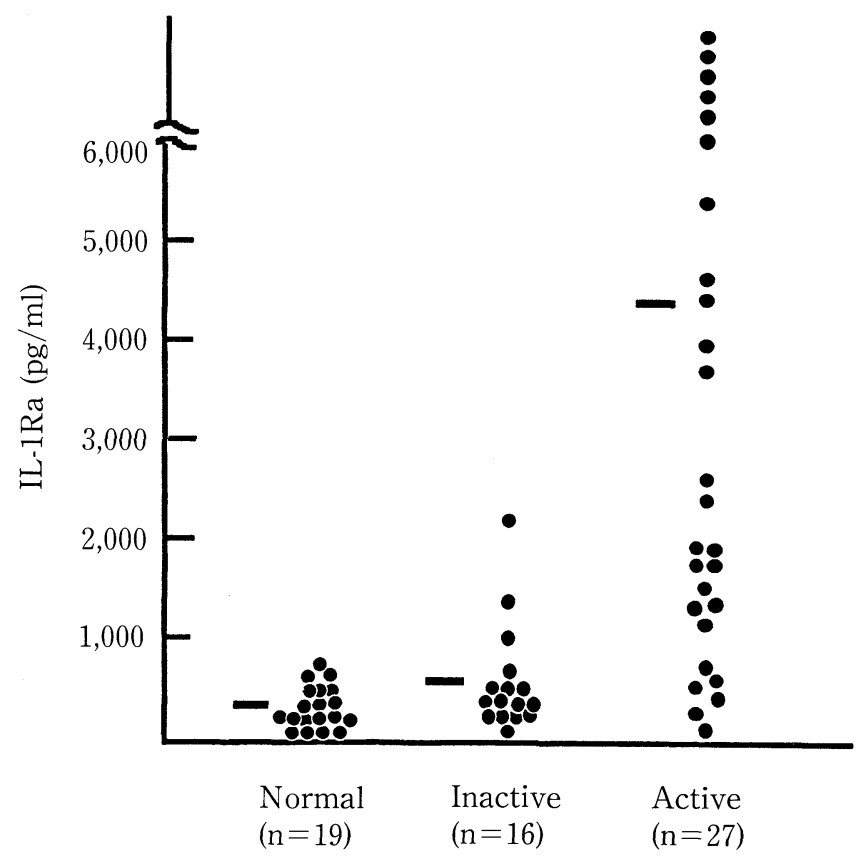

Figure 1. Serum IL-1Ra levels in patients with PM/DM. Serum IL-1Ra levels of 27 patients with active-stage PM/DM, 16 patients with inactive-stage PM/DM, and 19 normal controls were measured by ELISA. Horizontal short lines represent the mean of each group. 


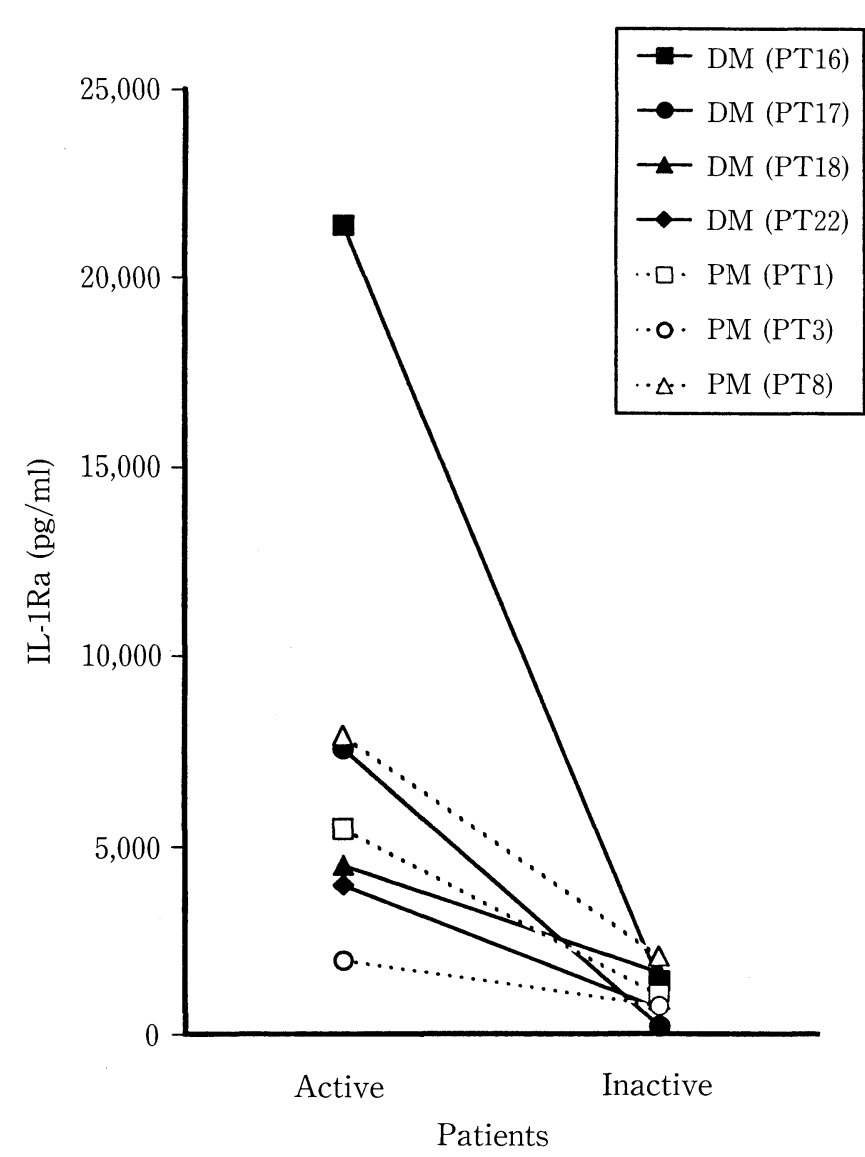

Figure 2. Changes in serum IL-1Ra levels before and after steroid therapy in patients with PM/DM. Serum IL-1Ra levels in $3 \mathrm{PM}$ and $4 \mathrm{DM}$ patients before and after steroid therapy were measured by ELISA. Patients received 30-100 mg/day of prednisolone at the start of therapy, and then the dose was gradually tapered. Samples were collected prior to steroid therapy and after reduction of the prednisolone dose to less than $20 \mathrm{mg} / \mathrm{day}$. The disease activity of all patients decreased following prednisolone therapy.

lone. The disease severity in all patients decreased following therapy. Serum levels of IL-1Ra decreased after steroid therapy in all patients tested, suggesting that IL-1Ra might be an useful marker for assessing the level of disease activity in PM/ DM. In contrast to IL-1Ra, serum levels of IL- $1 \beta$ were below the detection limits in all active-stage PM/DM patients (data not shown).

\section{Longitudinal evaluation of serum IL-1Ra levels in a patient with chronic DM}

Longitudinal evaluation of serum IL-1Ra levels was carried out to examine the relationship between serum IL-1Ra levels and the clinical course of a patient with chronic DM (PT16). This patient had CK concentrations as high as 7,315 IU/l and severe proximal muscle weakness prior to steroid therapy. After steroid therapy, serum CK levels declined rapidly to $44 \mathrm{IU} / l$. When the prednisolone dose was reduced, the levels of CK increased to approximately $300 \mathrm{IU} / l$ and did not change over more than 2 years. Serum aldolase levels were persistently elevated, and proximal muscle strength gradually improved but was still abnormal 2 years later. As shown in Fig. 3, serum levels of IL-1Ra were elevated initially at 21,388 $\mathrm{pg} / \mathrm{ml}$ and declined rapidly during high-dose prednisolone therapy. There was a significant relationship between IL-1Ra levels and CK levels during this initial response to therapy. When the prednisolone dose was reduced, serum IL-1Ra levels increased concomitant with increased CK levels.

\section{Relationship between serum CK or serum aldolase levels and serum IL-1Ra levels}

The relationship between serum IL-1Ra levels and muscle enzyme levels was determined in 27 patients with active PM/ DM. As shown in Fig. 4, serum IL-1Ra levels were not correlated with serum levels of $\mathrm{CK}(\mathrm{r}=0.359$; NS) or aldolase $(\mathrm{r}=0.108 ; \mathrm{NS})$.

\section{Expression of IL-1Ra mRNA in freshly isolated PBMC from PM/DM patients}

To investigate whether IL-1Ra is produced in the circulating blood of PM/DM patients, the expression of IL-1Ra mRNA was examined by Northern blot analysis of freshly isolated PBMC from patients with PM/DM. PBMC were isolated from 4 active-stage patients ( 2 with PM and 2 with DM), 1 active systemic lupus erythematosus (SLE) patient, and 7 normal controls. Serum levels of IL-1Ra in the 2 PM patients (PT3 and 8) were $1,804 \mathrm{pg} / \mathrm{ml}$ and $7,908 \mathrm{pg} / \mathrm{ml}$ and CK levels were 5,463 $\mathrm{IU} / l$ and $223 \mathrm{IU} / l$, respectively (right panel of Fig. 5). Patient 3 and 8 were receiving $30 \mathrm{mg} / \mathrm{day}$ and $40 \mathrm{mg} /$ day prednisolone, respectively, at the time of sampling. IL-1Ra mRNA was detectable in both these patients and also in the SLE patient, but not in normal controls. The time course of IL-1Ra gene expression is shown in the left panel of Fig. 5. Total RNA was prepared from samples collected at various time points from 2 DM patients (PT16 and 17). Serum levels of IL-1Ra and CK for patient 16 were $2,126 \mathrm{pg} / \mathrm{ml}$ and $111 \mathrm{IU} / l$, respectively, at the first sampling point, and $1,408 \mathrm{pg} / \mathrm{ml}$ and $132 \mathrm{IU} / \mathrm{l}$, respectively, at the second sampling point (33 days later). Serum levels of IL-1Ra and CK for patient 17 were $7,568 \mathrm{pg} / \mathrm{ml}$ and $5,889 \mathrm{IU} / \mathrm{l}$ at the first sampling point, and $1,838 \mathrm{pg} / \mathrm{ml}$ and 542 $\mathrm{IU} / \mathrm{l}$ at the second point (21 days later), and $201 \mathrm{pg} / \mathrm{ml}$ and 64 $\mathrm{IU} / l$, respectively, at the third point ( 54 days later after the initial sample). IL-1Ra mRNA was detectable in samples from both patients at the first sampling point, and there was a decrease in IL-1Ra mRNA expression at the second and third sampling points compared with that seen at the first point. IL1 Ra mRNA was not detectable in 4 normal controls. Beta-actin cDNA probe was used to determine the quantity of RNA in each lane on the Northern blots. The levels of $\beta$-actin mRNA were similar in all samples (data not shown).

\section{Constitutive IL-1Ra production by monocytes in PM/DM pa- tients}

The levels of IL-1Ra in the culture supernatants of unstimu- 


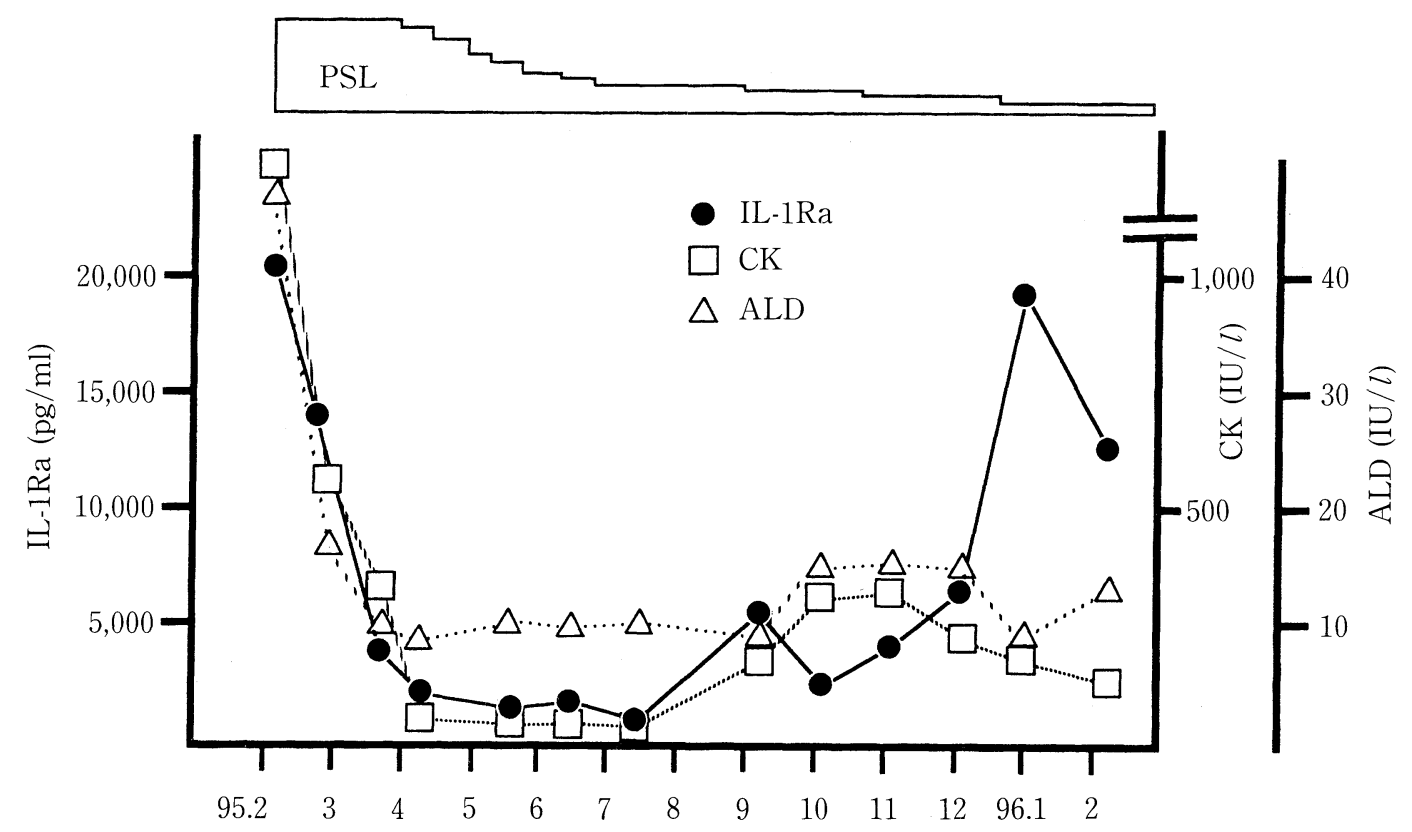

Figure 3. Longitudinal evaluation of serum IL-1Ra levels in a patient with chronic DM. Changes in IL-1Ra $(\bigcirc)$, CK $(\square)$, and aldolase $(\triangle)$ levels were evaluated during the course of this study. Data are from a 16-year-old man (PT16) with elevated levels of CK (7,315 IU/l) and aldolase (51.4 IU/l) and severe proximal muscle weakness at the time of diagnosis. Muscle biopsy showed (1) heavy lymphocyte infiltration around perivascular areas and (2) necrosis of perifascicular muscle fibers. A skin biopsy showed lymphocytic infiltration around the vessels of the dermis. Serum levels of CK decreased rapidly during therapy with high-dose prednisolone $(100 \mathrm{mg} / \mathrm{day}$ initial dose). After reducing the prednisolone dose, the levels were again elevated and remained elevated higher than those observed in normal individuals for more than 2 years. Serum levels of aldolase were also decreased but elevated persistently over a period of more than 2 years. Initially, serum IL-1Ra levels were elevated at $21,388 \mathrm{pg} / \mathrm{ml}$ and declined rapidly to $1,408 \mathrm{pg} / \mathrm{ml}$, and then increased concomitant with the increase in disease activity.

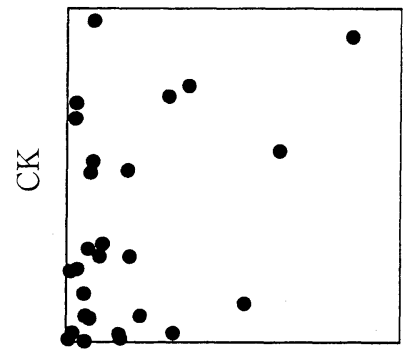

IL-1Ra

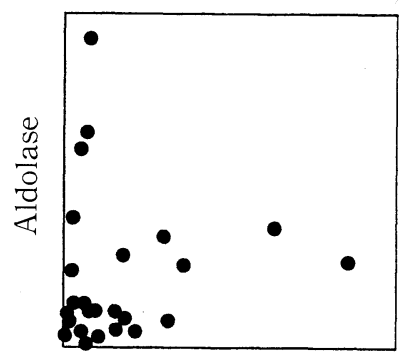

IL-1Ra
Figure 4. Relationship between serum CK or aldolase levels and serum IL-1Ra levels. The correlation between serum IL1Ra levels and serum CK levels, and between serum IL-1Ra levels and serum aldolase levels in 27 PM/DM patients were evaluated at the time of diagnosis.

lated monocytes from patients with PM/DM were measured. Monocytes from normal controls and PM/DM patients were incubated for 24 hours, and the supernatants were then tested for the presence of IL-1Ra by ELISA. The results of three rep- resentative experiments are shown in Fig. 6. IL-1Ra was detectable in culture supernatants of unstimulated monocytes from both normal controls and PM/DM patients. In 2 of 3 experiments, IL-1Ra concentrations were increased significantly in $\mathrm{PM} / \mathrm{DM}$ patients compared with concentrations in normal controls $(6,688 \mathrm{pg} / \mathrm{ml}$ vs $645 \mathrm{pg} / \mathrm{ml}$ in Exp. 1, 8,330 pg/ml vs 510 $\mathrm{pg} / \mathrm{ml}$ in Exp. 3). Based on these results and the Northern blot analysis, we conclude that a major source of elevated levels of IL-1Ra in the serum of PM/DM patients may be monocytes in the circulating blood.

\section{Allelic polymorphism in IL-1Ra gene in PM/DM patients}

IL-1Ra gene polymorphism in patients with PM/DM was examined to investigate whether a particular allele may influences circulating IL-1Ra concentrations. Twenty-one PM/DM patients and 15 normal controls were typed for a VNTR polymorphism in intron 2 of the IL-1Ra gene. Genotypes were determined by PCR typing as described in Patients and Methods. Table 2 showed the frequency of IL-1Ra alleles in patients and normal controls. All PM/DM patients and 12/15 (80\%) of normal controls were homozygous for the A1 allele (4 copies of the 86-bp sequence), suggesting that there were no significant 


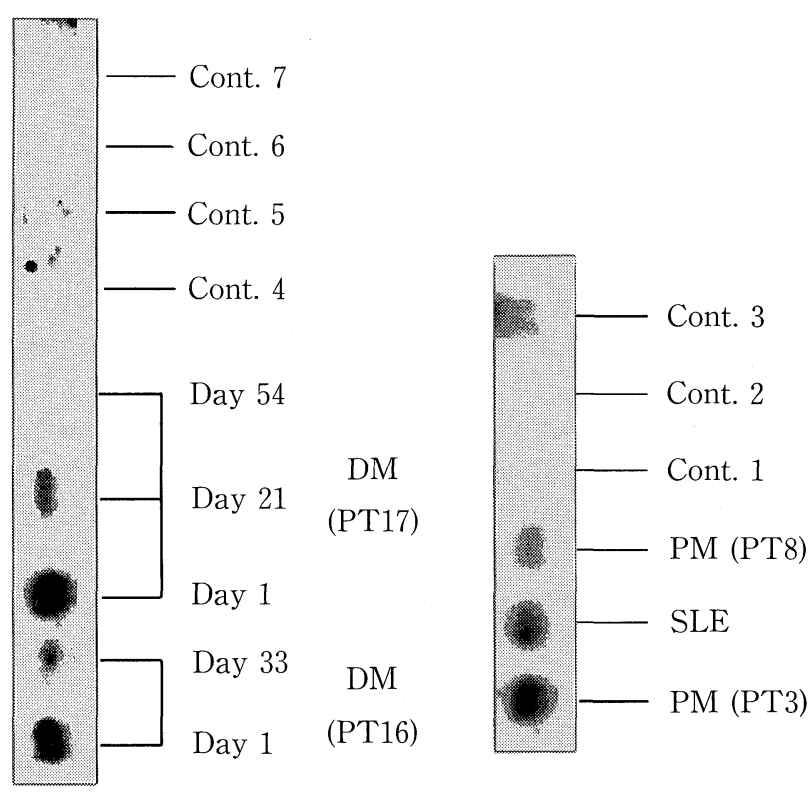

Figure 5. IL-1Ra mRNA expression in freshly isolated PBMC from PM/DM patients and normal controls. Total cellular RNA was extracted from freshly isolated PBMC from 4 PM/DM patients, 1 SLE patient, and 7 normal controls, and hybridized with an IL-1Ra cDNA probe. Right panel consisted of 3 normal controls (Cont. 1-3), 1 SLE patient, and 2 PM patients (PT3 and PT8). Left panel consisted of 4 normal controls (Cont. 4-7) and 2 DM patients (PT16 and 17).

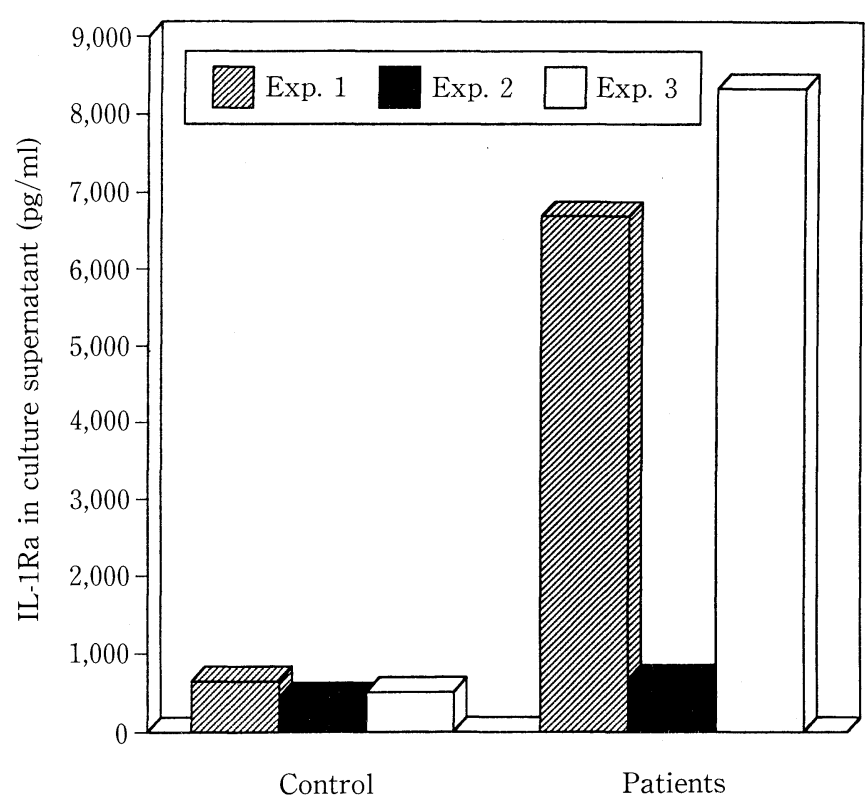

Figure 6. Constitutive IL-1Ra production by monocytes in PM/DM patients. Monocytes $\left(1 \times 10^{5}\right.$ cells $)$ from 2 PM patients (PT2 and 7), 1 DM (PT18), and 3 normal controls were cultured with medium alone for 24 hours, and then IL-1Ra levels in culture supernatants were measured by ELISA.

Table 2. IL-1Ra Gene Polymorphism* in patients with PM/DM

\begin{tabular}{|c|c|c|c|c|c|c|}
\hline & \multicolumn{3}{|c|}{ Genotype (number) } & \multicolumn{3}{|c|}{ Allele frequency $(\%)$} \\
\hline & $\mathrm{A} 1 / \mathrm{A} 1$ * & $\mathrm{A} 1 / \mathrm{A} 2$ & A1/A4 & A1 & $\mathrm{A} 2$ & A4 \\
\hline Control $(n=15)$ & 12 & 2 & 1 & 90 & 6.6 & 3.3 \\
\hline $\mathrm{PM} / \mathrm{DM}(\mathrm{n}=21)$ & 21 & 0 & 0 & 100 & 0 & 0 \\
\hline
\end{tabular}

*Polymorphism in IL-1Ra gene is caused by a variable copy number of a $86 \mathrm{bp}$ sequence in intron $2 .{ }^{*} \mathrm{~A} 1$ (410 bp), A2 (240 bp), and A4 (325 bp) alleles correspond to 4,2 , and 3 copies of the 86 bp sequence, respectively.

differences in allele frequencies between the PM/DM patients and normal controls.

\section{Discussion}

In the present study, serum IL-1Ra levels were measured serially in patients with active-stage PM/DM. Our results showed that serum IL-1Ra levels are significantly higher in patients with active-stage PM/DM than in patients with inactive-stage PM/DM or in normal controls. Longitudinal evaluation of serum IL-1Ra levels showed that the magnitude of change in serum IL-1Ra level was closely related to the clini- cal improvement of myositis. IL-1Ra mRNA levels in freshly isolated PBMC from active PM/DM patients were higher than levels in normal controls. Moreover, levels of IL-1Ra protein in culture supernatants from unstimulated monocytes were elevated in patients with PM/DM compared with levels in normal controls. These data suggest that monocytes in the circulating blood may be a major source of IL-1Ra in the serum of PM/DM patients.

Relatively little information concerning endogenous production of cytokines in PM/DM patients is available at the present time, but Wolf and Baethge (4) found increased levels of IL$1 \alpha$ in sera from PM/DM patients. Immunohistochemical stud- 
ies of muscle biopsy specimens revealed that IL- $1 \alpha$ protein is expressed in endothelial cells of capillaries, arterioles, and venules in areas surrounded by inflammatory cells, and both IL- $1 \alpha$ and IL- $1 \beta$ were expressed in mononuclear inflammatory cells and muscle fibers of patients with PM/DM $(5,19$, 20 ). Although the IL- $1 \alpha$ and IL-1 $\beta$ expression profiles in these studies were varied and inconsistent between patients with PM/ DM, similar results were obtained from reverse transcription (RT)-PCR studies that examined cytokine mRNA expression in muscle specimens $(21,22)$. These observations suggest that the IL-1- mediated immune response plays an important role in the pathogenesis and progression of PM/DM.

IL-1Ra is a specific receptor antagonist that competitively inhibits binding of IL- $1 \alpha$ and IL- $1 \beta$ to type I and type II IL- 1 receptors, respectively. IL-1Ra has been shown to antagonize the effects of IL- 1 in various in vitro systems and in animal models of disease. Furthermore, elevated serum levels of IL$1 \mathrm{Ra}$ have been reported in patients with juvenile chronic arthritis (8), PM (9), SLE (10), and rheumatoid arthritis (RA) $(13,14)$. RA patients exhibited a lower IL-1Ra to IL-1 $\beta$ ratio in plasma both prior to and following surgery in comparison to patients with osteoarthritis or osteomyelitis. This suggests that IL-1 Ra production may be reduced or inadequate in RA patients (14). Furthermore, IL-1Ra production was enhanced, and the IL-1 $\beta$ to IL-1Ra ratio was decreased in peripheral blood monocytes from patients with RA after clinical response to treatment with methotrexate or gold injections $(23,24)$. IL-1Ra levels also were elevated in the synovial fluid of patients with RA. Neutrophils might be the major source of IL-1Ra in rheumatoid synovial fluids, even though these cells produce less IL-1Ra and more IL-1 $\beta$ in comparison to peripheral blood neutrophils (25).

There have been few reports of IL-1Ra in PM/DM. Gabay et al (9) found that serum IL-1Ra levels were significantly higher in $15 \mathrm{PM} / \mathrm{DM}$ patients than in 12 normal controls and that IL-1Ra levels were elevated in patients with active myositis and decreased in response to steroid treatment. These findings were similar to our study of 27 patients with active-stage PM/DM. Taken together, these data suggest that IL-1Ra might be a useful marker for monitoring the clinical course of myositis and classifying the levels of PM/DM activity. However, in contrast to previous findings, there was no significant correlation between the serum muscle enzyme levels and IL-1Ra levels in our study. Although the reason for this discrepancy is not clear, it may be related to observations that serum muscle enzymes are not elevated in 3.2 to $36 \%$ of newly diagnosed patients (26-29). Thus, elevated serum muscle enzyme levels are not sufficient for the evaluation of disease activity in PM/DM.

A previous study indicated that IL-1Ra may contribute to the regulation of IL-1-mediated diseases (30). Because IL-1 has been implicated in the pathogenesis of myositis, it could be that IL-1Ra in PM/DM contributes to the regulation of inflammatory events in diseased muscle. The source of IL-1Ra in PM/DM has not yet been established; however, determining the origin of serum IL-1Ra may provide useful information on the pathogenesis of myositis. Therefore, we analyzed IL-1Ra
mRNA expression in freshly isolated $\mathrm{PBMC}$ from patients with $\mathrm{PM} / \mathrm{DM}$ and measured IL-1Ra protein levels in supernatants from unstimulated monocytes from patients.

Our results clearly showed that circulating monocytes might be a major source of IL-1Ra in the sera of PM/DM patients, although we cannot neglect the possibility that residual lymphocytes in the monocyte fraction are another source of IL$1 \mathrm{Ra}$ in PM/DM. There are several possible mechanisms for elevation of IL-1Ra levels in PM/DM. First, activated monocytes and macrophages are stimulated to produce both IL-1 and IL-1Ra via an autocrine mechanism in the cytokine network $(31,32)$. This reflects induction of the inflammatory state and homeostatic regulation during myositis. Because IL-1 $\beta$ levels were below the detectable limits in PM/DM patients, it is possible that the concentrations of IL-1Ra in patients with active PM/DM may be high enough to block IL- $1 \beta$ activity. Secondly, IL-1Ra is produced by activated circulating monocytes as a result of increased IL-1 at the site of inflammation. Many studies using immunohistochemistry and RT-PCR techniques have indicated that IL-1 is produced by mononuclear inflammatory cells, atrophic muscle fibers in diseased muscle, and endothelial cells in the vascular wall. This cytokine may penetrate the tissue and enter the circulation. Although IL-1Ra levels are thought to increase in response to endogenous IL-1 (33), IL-1Ra levels may not be sufficient to block the effect of IL-1 in myositis. Thirdly, the elevation of serum IL-1Ra levels may be derived not only from peripheral monocytes and macrophages but also from other cell types including inflammatory cells in muscle tissue or hepatic cells in the liver (34). We are now investigating these possibilities using muscle biopsy specimens from normal controls and PM/DM patients.

Recently, IL-1Ra gene polymorphisms have been associated with several inflammatory diseases (35-37). Five alleles were identified by analysis of the 86-bp VNTR in the second intron of IL-1Ra. Blakemore et al (38) reported an increase in both frequency and carriage rate of 2 repeat (the IL1RN*2) alleles, which contains 2 copies of the repeat sequence, in Caucasian patients with SLE. They also found an association between this allele and the severity of SLE and the presence of photosensitivity and discoid skin lesions. This result was particularly interesting because serum IL-1Ra levels were closely correlated with the severity of SLE. In addition, the repeated region in the second intron of the IL-1Ra gene contains 3 possible transcription factor binding sites (39). However, the frequency of IL1RN*2 in Japanese controls was considerably lower than that reported in Caucasian controls (6.6\% in Japanese vs $24.1 \%$ in Caucasian) as described by Suzuki et al (40). Furthermore, all PM/DM patients were homozygous for IL1RN*1 (4 repeats) in our study. Therefore, it seems unlikely that the IL1RN*2 allele influences the severlity of myositis in Japanese patients with PM/DM.

In conclusion, our study demonstrates increased gene expression and elevation of serum levels of IL-1Ra in patients with active-stage PM/DM. These results suggest that higher levels of serum IL-1Ra may reflect increased IL-1Ra production in myositis, and that IL-1Ra may regulate IL-1-mediated 


\section{IL-1Ra in PM/DM}

muscle fiber damage in PM/DM.

\section{References}

1) Hohlfeld R, Engel AG. The immunobiology of muscle. Immunol Today 15: 269-274, 1994.

2) Kalovidouris AE. Mechanisms of inflammation and histopathology in inflammatory myopathy. Rheum Dis Clin North Am 20: 881-897, 1994.

3) Hohlfeld R, Engel AG, Goebels N, Behrens L. Cellular immune mechanisms in inflammatory myopathies. Curr Opin Rheum 9: 520-526, 1997.

4) Wolf RE, Baethge BA. Interleukin-1 $\alpha$, Interleukin-2, and soluble interleukin-2 receptors in polymyositis. Arthritis Rheum 33: 1007-1014, 1990.

5) Lundberg I, Ulfgren AK, Nyberg P, Andersson U, Klareskog L. Cytokine production in muscle tissue of patients with idiopathic inflammatory myopathies. Arthritis Rheum 40: 865-874, 1997.

6) Lennard AC. Interleukin-1 receptor antagonist. Crit Rev Immunol 15: 77-105, 1995.

7) Arend WP, Malyak M, Guthridge CJ, Gabay C. Interleukin-1 receptor antagonist : role in biology. Annu Rev Immunol 16: 27-55, 1998.

8) De Benedetti F, Pignatti P, Massa M, Sartirana P, Ravelli A, Martini A. Circulating levels of interleukin $1 \beta$ and of interleukin-1 receptor antagonist in systemic juvenile chronic arthritis. Clin Exp Rheum 13: 779-784, 1995.

9) Gabay C, Gay-Croisier F, Roux-Lombard P, et al. Elevated serum levels of interleukin-1 receptor antagonist in polymyositis/dermatomyositis: A biologic marker of disease activity with a possible role in the lack of acute-phase protein response. Arthritis Rheum 37: 1744-1751, 1994.

10) Suzuki $H$, Takemura $H$, Kashiwagi $H$. Interleukin-1 receptor antagonist in patients with active systemic lupus erythematosus: enhanced production by monocytes and correlation with disease activity. Arthritis Rheum 38: 1055-1059, 1995.

11) Casini-Raggi V, Kam L, Chong YJT, Fiocchi C, Pizarro TT, Cominelli F. Mucosal imbalance of IL-1 and IL-1 receptor antagonist in inflammatory bowel disease. A novel mechanism of chronic intestinal inflammation. $\mathbf{J}$ Immunol 154: 2434-2440, 1995.

12) Yoshida $S$, Hashimoto $S$, Nakayama $T$, Kobayashi $T$, Koizumi A, Horie T. Elevation of serum soluble tumour necrosis factor (TNF) receptor and IL-1 receptor antagonist levels in bronchial asthma. Clin Exp Immunol 106: 73-78, 1996.

13) Malyak M, Swaney RE, Arend WP. Levels of synovial fluid interleukin1 receptor antagonist in rheumatoid arthritis and other arthropathies: Potential contribution from synovial fluid neutrophils. Arthritis Rheum 36: 781-789, 1993.

14) Chikanza IC, Roux-Lombard P, Dayer JM, Panayi GS. Dysregulation of the in vivo production of interleukin-1 receptor antagonist in patients with rheumatoid arthritis: Pathogenetic implications. Arthritis Rheum 38: 642648, 1995.

15) Hashimoto $S$, Koh $K$, Tomita $Y$, et al. TNF- $\alpha$ regulates IL-4-induced $F c \varepsilon$ $\mathrm{RII} / \mathrm{CD} 23$ gene expression and soluble Fc $\varepsilon$ RII release by human monocytes. Int Immunol 5: 705-713, 1994.

16) Eisenberg SP, Evans RJ, Arend WP, et al. Primary structure and functional expression from complementary DNA of a human interleukin-1 receptor antagonist. Nature 343: 341-346, 1990.

17) Yamagami $K$, Tomita $Y$, Takei $M$, Sawada $S$, Horie $T$. Increased gene expression of TNF- $\alpha$ and IL- $1 \beta$ in peripheral blood mononuclear cells from patients with systemic lupus erythematosus. Nihon Univ J Med 36: 297-309, 1994.

18) Tarlow JK, Blakemore AIF, Lennard A, et al. Polymorphism in human IL-1 receptor antagonist gene intron 2 is caused by variable numbers of an 86-bp tandem repeat. Hum Genet 91: 403-404, 1993.

19) Tews DS, Goebel HH. Cytokine expression profile in idiopathic inflammatory myopathies. J Neuropathol Exp Neurol 55: 342-347, 1996.

20) Authier FJ, Mhiri C, Chazaud B, et al. Interleukin-1 expression in inflammatory myopathies: evidence of marked immunoreactivity in sarcoid granulomas and muscle fibres showing ischaemic and regenerative changes. Neuropathol Appl Neurobiol 23: 132-140, 1997.

21) Lundberg I, Brengman JM, Engel AG. Analysis of cytokine expression in muscle in inflammatory myopathies, Duchenne dystrophy, and non-weak controls. J Neuroimmunol 63: 9-16, 1995.

22) Lepidi H, Frances V, Figarella-Branger D, Bartoli C, Machado-Baeta A, Pellissier JF. Local expression of cytokines in idiopathic inflammatory myopathies. Neuropathol Appl Neurobiol 24: 73-79, 1998.

23) Seitz M, Loetscher P, Dewald B, et al. Methotrexate action in rheumatoid arthritis: Stimulation of cytokine inhibitor and inhibition of chemokine production by peripheral blood mononuclear cells. Br J Rheumatol 34: 602-609, 1995.

24) Seitz M, Loetscher P, Dewald B, et al. Interleukin-1 (IL-1) receptor antagonist, soluble tumor necrosis factor receptors, IL- $1 \beta$, and IL-8: Markers of remission in rheumatoid arthritis during treatment with methotrexate. J Rheumatol 23: 1512-1516, 1996.

25) Shingu M, Fujikawa $Y$, Wada T, Nonaka S, Nobunaga M. Increased IL-1 receptor antagonist (IL-1ra) production and decreased IL-1 $\beta / \mathrm{IL}-1$ ra ratio in mononuclear cells from rheumatoid arthritis patients. $\mathrm{Br} \mathbf{J}$ Rheumatol 34: 24-30, 1995.

26) Bohan A, Peter JB, Bowman RL, Pearson CM. A computer-assisted analysis of 153 patients with polymyositis and dermatomyositis. Medicine (Boltimore) 56: 255-286, 1977.

27) Ramirez G, Asherson RA, Khamashta MA, Cervera R, D'Cruz D, Hughes GRV. Adult-onset polymyositis-dermatomyositis : description of 25 patients with emphasis on treatment. Semin Arthritis Rheum 20: 114-120, 1990.

28) Ehrenstein MR, Snaith ML, Isenberg DA. Idiopathic myositis: a rheumatological view. Ann Rheum Dis 51: 41-44, 1992.

29) Mader R, Keystone EC. Inflammatory myopathy - do we have adequate measures of the treatment response? (editorial). J Rheumatol 20: 11051107, 1993.

30) Weckmann AL, Alcocer-Varela J. Cytokine inhibitors in autoimmune disease. Semin Arthritis Rheum 26: 539-557, 1996.

31) Arend WP, Smith MF Jr, Janson RW, Joslin FG. IL-1 receptor antagonist and IL- $1 \beta$ production in human monocytes are regulated differently. $\mathbf{J}$ Immunol 147: 1530-1536, 1991.

32) Andersson J, Bjork L, Dinarello CA, Towbin H, Andersson U. Lipopolysaccharide induces human interleukin-1 receptor antagonist and interleukin-1 production in the same cell. Eur J Immunol 22: 2617-2623, 1992.

33) Wahl SM, Costa GL, Corcoran M, Wahl LM, Berger AE. Transforming growth factor- $\beta$ mediates IL-1-dependent induction of IL-1 receptor antagonist. J Immunol 150: 3553-3560, 1993.

34) Gabay C, Smith Jr MF, Eidlen D, Arend WP. Interleukin 1 receptor antagonist (IL-1Ra) is an acute-phase protein. J Clin Invest 99: 2930-2940, 1997.

35) Mansfield JC, Holden H, Tarlow JK, et al. Novel genetic association between ulcerative colitis and the anti-inflammatory cytokine interleukin-1 receptor antagonist. Gastroenterology 106: 637-642, 1994.

36) Bioque G, Crusius JBA, Koutroubakis I, et al. Allelic polymorphism in IL-1 $\beta$ and interleukin 1 receptor antagonist (IL-1Ra) genes in inflammatory bowel disease. Clin Exp Immunol 102: 379-383, 1995.

37) Tarlow JK, Clay FE, Cork MJ, et al. Severrity of alopecia areata is associated with a polymorphism in the interleukin-1 receptor antagonist gene. J Invest Dermatol 103: 387-390, 1994.

38) Blakemore AIF, Tarlow JK, Cork MJ, Gordon C, Emery P, Duff GW Interleukin-1 receptor antagonist gene polymorphism as a disease severity factor in systemic lupus erythematosus. Arthritis Rheum 37: 1380$1385,1994$.

39) Danis VA, Millincton M, Hyland VJ, Grennan D. Cytokine production by normal human monocytes: inter-subject variation and relationship to an IL-1 receptor antagonist (IL-1Ra) gene polymorphism. Clin Exp Immunol 99: 303-310, 1995.

40) Suzuki H, Matsui Y, Kashiwagi H. Interleukin-1 receptor antagonist gene polymorphism in Japanese patients with systemic lupus erythematosus. Arthritis Rheum 40: 389-390, 1997. 